\title{
Operative cystoscopy in the neonatal period
}

\author{
Salvatore Arena, Tiziana Russo, Patrizia Perrone, Carmelo Romeo \\ Unit of Paediatric Surgery, Department of Human Pathology in Adult and Developmental Age, \\ University of Messina, Messina, Italy
}

\begin{abstract}
Aim of the study is to report the experience in the last three years about endourological treatment of newborns affected by genito- and urinary malformation, implying critical urinary tract dilatation and bladder mass requiring a neonatal operative management. Seven four males and three female - patients were treated cystoscopically during the neonatal period. Three newborns with a posterior urethral valves (PUV), underwent a successful ablation of PUV. In a male with infected persistent large mullerian duct and subsequent acute urinary retention, a cystoscopically-assisted catheterization was performed. Two females, one with cloaca and the other with high persistent urogenital sinus and massive associated hydrometrocolpos underwent a cystoscopical drainage of the vagina and a positioning of a balloon catheter into the bladder. Another female with a bladder mass had a endoscopical biopsy. Thanks to modern neonatal operative urethrocystoscope, today is possible to treat early many pathological genito-urinary conditions in newborns.
\end{abstract}

\section{Introduction}

The coming of prenatal ultrasonography modified the approach to the genito-urinary malformations, allowing a their early diagnosis and treatment and reducing the associated morbidity. ${ }^{1-3}$ Prenatal diagnosis includes dilatative genito-urinary tract malformation and, even if rarely, urinary masses. Aim of the study is to report our experience in the last three years about the endourological treatment of

Correspondence: Salvatore Arena, Unit of Paediatric Surgery, Department of Human Pathology in Adult and Developmental Age "Gaetano Barresi", University of Messina, viale Gazzi, 98124 Messina, Italy.

Tel +39.090.2213014.

E-mail: salarena@unime.it

Key words: Operative cystoscopy; Posterior urethral valve; Persistent urogenital sinus; Bladder mass; Cloaca.

Received for publication: 7 July 2016.

Accepted for publication: 30 November 2016.

This work is licensed under a Creative Commons Attribution NonCommercial 4.0 License (CC BY-NC 4.0).

CCopyright S. Arena et al., 2016

Licensee PAGEPress, Italy

La Pediatria Medica e Chirurgica 2016; 38:136

doi:10.4081/pmc.2016.136 newborns affected by genito-urinary malformation implying critical urinary tract dilatation and by bladder mass requiring a neonatal operative management.

\section{Case Report}

During the period between 2013 and 2015, seven patients were treated cystoscopically during the neonatal period, four males and three females. All cystoscopies were performed with a 8/9.5 operative urethrocystoscope.

Three newborns have a prenatal diagnosis of megabladder, severe urinary tract dilatation and urinary retention. At birth, an indwelling catheter was positioned in the bladder. A voiding urethrocystogram documented in all cases posterior urethral valves (PUV) with high grade vesico-ureteral reflux in two cases. After 7-12 days, patients underwent ablation of posterior urethral valves (Figure 1). During post-operative period, newborns showed a good patency of the urethra after operation, with progressive disappearances of the upper urinary tract dilatation and vesico-ureteral reflux resolution. In all patients, a gradual functional restoring of the renal function was experienced.

A male displayed feminization of external genitalia, scrotal hypospadias, bilateral palpable undescended testis, fever and acute urinary retention. After an unsuccessful attempt of catheterization, we performed a cystoscopy that showed a large infected persistent mullurian duct. An endoscopical drainage of the abscess was done and a tip opened Foley catheter was passed after introduction of a guide-wire resolving the acute urinary retention.

One female neonate, with prenatal diagnosis of hydrometrocolpos with transverse vaginal septum, fetal ascites and severe upper urinary dilatation, registered respiratory distress secondary to massive abdominal distention. After radiological confirmation of a cloaca, a cystoscopical drainage of the vaginas was performed and a balloon catheter was introduced into the bladder on guide-wire (Figure 2).

In the immediate post-operative period, the patients had a quick resolution of upper urinary dilatation and a recovery of the general medical conditions.

A female newborn, with prenatal diagnosis of mesenteric cyst and bilateral hydronephrosis, was urgently transferred at our institution. At observation of external genitalia, a diagnosis of urogenital sinus was done. Ultrasonography confirmed the presence of a big hydrometrocolpos with bilateral dilatation of the upper urinary tract and ascites. A drainage of the vagina was performed undercistoscopy and a balloon catheter was performed on guide-wire (Figure 3).

A female was referred at our institution for rectal bleeding. An abdominal ultrasonography showed a bladder mass. For this reason, a cystoscopy was done showing a buch of grapes bladder tumor, macroscopically similar to a vesical rhabdomyosarcoma. An endoscopical biopsy (Figure 4) was performed and histological examination excluded a malignant origin of the tumor (it was a polypoid cystitis). 


\section{Discussion}

Thanks to modern neonatal operative urethrocystoscope, today it is possible to treat early many pathological conditions implying a severe upper urinary tract dilatation, hydrocolpos with ascites or requiring a

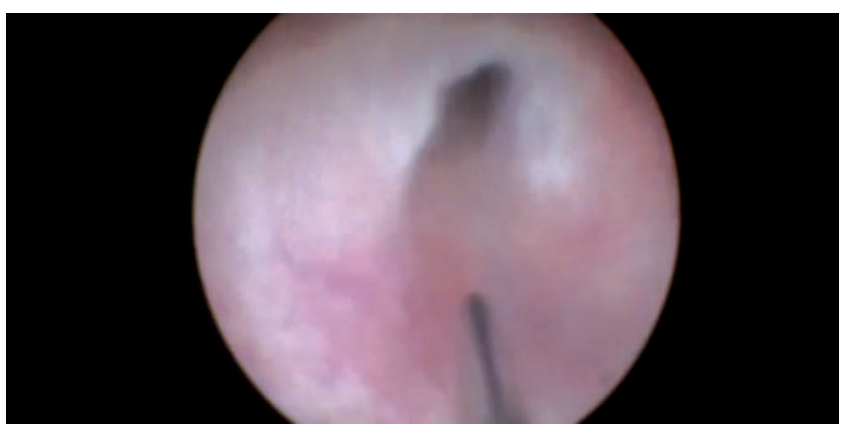

Figure 1. A posterior urethral valve is shown.

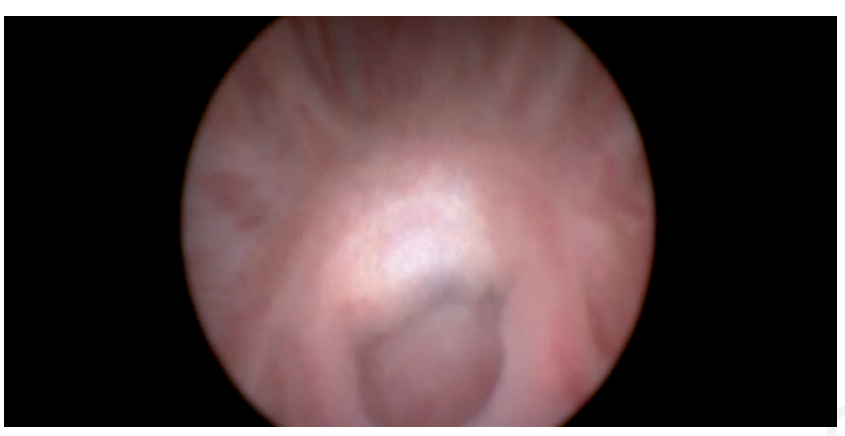

Figure 2. A large persistent mullerian duct can be seen in a newborn.

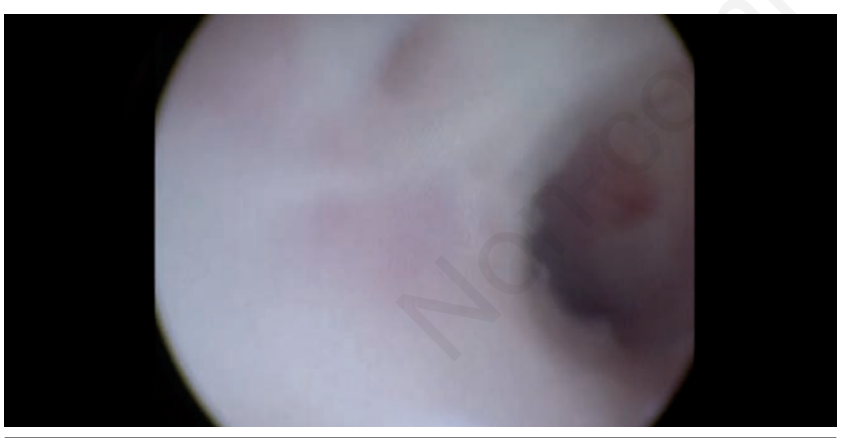

Figure 3. A common channel with two orifices (dilated vagina and urethral orifice) is displayed in a female with cloaca.

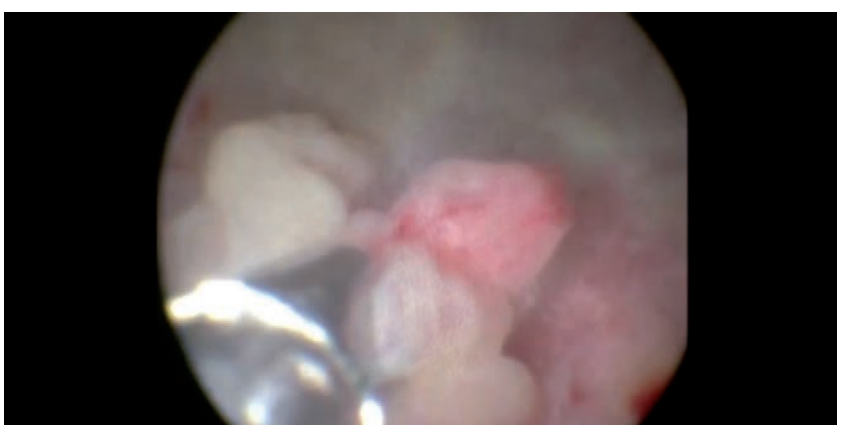

Figure 4. A biopsy performed in a neonatal bladder mass. rapid diagnosis for the suspected malignant origin. In cases of PUV with neonatal onset, an alternative to neonatal endourological primary valve ablation is the vesicostomy, an invasive and poorly accepted by patients and parents procedure. 4,5

Persistent mullerian duct syndrome is a rare form of internal male pseudohermaphroditism in which Mullerian duct derivatives are seen in a karyotypically male patients. 6,7 This duct, originated by an anomaly in sexual differentiation, can have large size and to predispose to urinary infection with acute urinary retention. ${ }^{7}$

\section{Conclusions}

Fetal ascites can occur due to many heterogeneous disorders. Its association with hydrometrocolpos owing to persistent urogenital sinus and cloaca is extremely rare. Fetal ascites in these cases was due to fetal urine draining through falloppian tubes into the abdomen as a result of vesico-vaginal fistula and distal vaginal atresia. ${ }^{8-10}$ Endoscopical drainage of internal genitalia allows an urgent miniinvasive decompression of the hydrometrocolpos and of the upper urinary tract dilatation, thus to permit a recovery of the general conditions of the female neonated, allowing, by the way, a detailed study of these complex abnormalities. Last but not least, neonatal diagnostic/operative cystoscopy permits a miniinvasive diagnosis in the very rare neonatal bladder mass. ${ }^{11}$ All this is possible for the miniaturization of the neonatal endourological instrumentation and by experience of the pediatric urologists, making it possible to work safely and with small babies' minimal discomfort.

\section{References}

1. Andrés-Jensen L, Jørgensen FS, Thorup J, et al. The outcome of antenatal ultrasound diagnosed anomalies of the kidney and urinary tract in a large Danish birth cohort. Arch Dis Child 2016;101:819-24.

2. Sadeghi-Bojd S, Kajbafzadeh AM, Ansari-Moghadam A, Rashidi S. Postnatal evaluation and outcome of prenatal hydronephrosis. Iran J Pediatr 2016;26:e3667.

3. Taori K, Krishnan V, Sharbidre KG, et al. Prenatal sonographic diagnosis of fetal persistent urogenital sinus with congenital hydrocolpos. Ultrasound Obstet Gynecol 2010;36:641-3.

4. Hosseini SM, Zarenezhad M, Kamali M, et al. Comparison of early neonatal valve ablation with vesicostomy in patient with posterior urethral valve. Afr J Paediatr Surg 2015;12:270-2.

5. Godbole P, Wade A, Mushtaq I, Wilcox DT. Vesicostomy vs primary ablation for posterior urethral valves: always a difference in outcome? J Pediatr Urol 2007;3:273-5.

6. Saleem M, Ather U, Mirza B, et al. Persistent mullerian duct syndrome: a 24-year experience. J Pediatr Surg 2016;51:1721-4.

7. Farhat W, Akel S, Hemady K. Urinary retention secondary to müllerian duct remnant in an infant. Can J Urol 1998;5:482-4.

8. Nigam A, Kumar M, Gulati S. Fetal ascites and hydrometrocolpos due to persistent urogenital sinus and cloaca: a rare congenital anomaly and review of literature. BMJ Case Rep 2014;19:2014.

9. Peña A, Levitt MA, Hong A, Midulla P. Surgical management of cloacal. malformations: a review of 339 patients. J Pediatr Surg 2004;39:470-9.

10. Bischoff A. The surgical treatment of cloaca. Semin Pediatr Surg 2016;25:102-7.

11. Arena S, Barresi V, Manganaro A, et al. Bladder mass in newborn: case report and review of literature. Urology 2015;86:1004-7. 